\title{
Evaluation of the Measles Surveillance System in Kaduna State, Nigeria (2010-2012)
}

\author{
Celestine A. Ameh*1, Muawiyyah B. Sufiyan², Matthew Jacob ${ }^{3}$, Ndadilnasiya E. Waziri ${ }^{1}$ and
} Adebola T. Olayinka²

1. Nigerian Field Epidemiology and Laboratory Training Program, Abuja, Nigeria

2. Ahmadu Bello University Zaria, Nigeria

3. Kaduna State Primary Health Care Agency, Kaduna, Nigeria

\begin{abstract}
Objective: To evaluate the case-based measles surveillance system in Kaduna State of Nigeria and identify gaps in its operation.

Introduction: In Africa, approximately 13 million cases, 650,000 deaths due to measles occur annually, with sub-Saharan Africa having the highest morbidity and mortality. Measles infection is endemic in Nigeria and has been documented to occur all year round, despite high measles routine and supplemental immunization coverage. The frequent outbreaks of measles in Kaduna State prompted the need for the evaluation of the measles case-based surveillance system.
\end{abstract}

Methods: We interviewed stakeholders and conducted a retrospective record review of the measles case-based surveillance data from 2010 - 2012 and adapted the 2001 CDC guidelines on surveillance evaluation and the Framework for Evaluating Public Health Surveillance Systems for Early Detection of Outbreaks, to assess the systems usefulness, representativeness, timeliness, stability, acceptability and data quality. We calculated the annualized detection rate of measles and non-measles febrile rash, proportion of available results, proportion of LGAs (Districts) that investigated at least one case with blood, proportion of cases that were IgM positive and the incidence of measles. We compared the results with WHO(2004) recommended performance indicators to determine the quality and effectiveness of measles surveillance system.

Results: According to the Stakeholders, the case-based surveillance system was useful and acceptable. Median interval between specimen collection and release of result was 7 days (1 - 25 days) in 2010, 38 days (Range: 16 - 109 days) in 2011 and 11 days (Range: 1 - 105 days) in 2012. The annualized detection rate of measles rash in 2010 was 2.1 (target: ${ }^{3}$ 2), 1.0 (target: ${ }^{3}$ ) in 2011 and 1.4 (target: ${ }^{3} 2$ ) in 2012. The annualized detection rate of non-measles febrile rash in 2010 was 2.1 (target: ${ }^{3} 2$ ), 0.6 (target: ${ }^{3} 2$ ) in 2011 and 0.8 (target: ${ }^{3} 2$ ) in 2012. Case definitions are simple and understood by all the operators.

Conclusion: This evaluation showed that the surveillance system was still useful. Also, the efficiency and effectiveness of the laboratory component as captured by the "median interval between specimen collection and the release of results improved in 2010 and 2012 compared to 2011. However, there was a progressive decline in the timeliness and completeness of weekly reports in the years under review.

Keywords: Measles; Case-based; Surveillance; Evaluation; Nigeria 
Correspondence: Celestine Attah Ameh, Nigeria Field Epidemiology and Laboratory Training Program, No. 50 Haile Selassie Street, Asokoro, Abuja, Nigeria. E-mail: cameh1085@gmail.com, Phone: +2348035992494

DOI: $10.5210 /$ ojphi.v8i3.7089

Copyright @2016 the author(s)

This is an Open Access article. Authors own copyright of their articles appearing in the Online Journal of Public Health Informatics. Readers may copy articles without permission of the copyright owner(s), as long as the author and OJPHI are acknowledged in the copy and the copy is used for educational, not-for-profit purposes.

\section{Introduction}

Measles is an acute viral infectious disease and an important cause of childhood morbidity and mortality [1-5]. In 2010, the estimated annual measles incidence aggregated across all countries was 1.6 cases per 1000, resulting in about 139,000 deaths globally [6]. In Africa, about 13 million cases, 650,000 deaths occur annually, with sub-Saharan Africa having the highest morbidity and mortality $[7,8]$.

Measles is endemic in Nigeria and exhibits a seasonal pattern with increasing incidence during the dry season (November to May). The severity of this disease is higher in the northern part of Nigeria [9], due to the inadequate utilization of measles control strategies [6]. Outbreaks occur due to the high birth cohort, sub-optimal immunization coverage and the wide interval between follow-up campaigns, resulting in the accumulation of large numbers of susceptibles $[10,11]$. The burden of measles in Nigeria prior to the introduction of the accelerated measles control strategy in 2005 was high. For instance, in 1985, 3.6 million cases resulting in 108, 000 deaths were reported [12]. Following the implementation of the measles catch-up Supplementary Immunization Activities (SIAs) in 2005, there was a significant reduction in measles morbidity and mortality [10]. However, the post implementation phase of this strategy witnessed a non-linear increase in measles incidence [13]. Thus in 2006, 383 measles cases were reported in children less than 15 years (Annual Incidence Rate [AIR]: 0.6 cases /100,000 children). In 2007, it increased to 2,542 cases (AIR: 3.6 cases/100,000 children). A breakdown of cases in 2007, showed $62 \%$ to be aged between $1-4$ years, and $23 \%$ aged between $5-14$ years. In 2008, there was a further increase to 9,510 cases (AIR: 13.4 cases/100,000 children). By 2011, the number of measles cases had risen to 17,248 (AIR: 18.2 cases/100,000 children) [8]. Most of the cases occurred predominantly among younger children [6].

Despite high administrative estimates of measles vaccine coverage (>99\%) at first (routine) dose and during SIAs in Nigeria, outbreaks continue to occur [6,8,14]. About 30, 194, 254 and 169 measles outbreaks were reported in 2006, 2007, 2008 and 2009 respectively [11]. Furthermore, between epidemiological week 1 to 43 of 2013, 643 outbreaks were confirmed in $83 \%$ of the 774 LGAs of this country [15] with Kebbi and Kaduna States in northern Nigeria recording a significant proportion of these outbreaks $[8,10]$.

Inadequate surveillance and response capacity in any country can endanger its population. Unfortunately, developing countries, where there is the greatest risk for outbreaks, often lack the capacity to promptly detect and adequately respond to these outbreaks [16]. In Nigeria, findings had shown that most of the measles outbreaks were detected too late resulting in either no or late response with minimal impact [17]. The frequent measles outbreaks in Kaduna State prompted the need to evaluate the measles case-based surveillance system attributes and identify gaps in its operation. 


\section{Methods}

\section{Area covered by the surveillance system}

Kaduna State (Province) is made up of 23 Local Government Areas (LGAs)/Districts and 255 political wards. It occupies a land area of $46,053 \mathrm{~km}^{2}$ and a population of 7.1 million inhabitants (2011 census estimate) [18] made up of 281,047 children less than 1 year of age, 1.2 million between the ages of 1-4 years, 1.8 million between $5-14$ years, 458,800 between $15-18$ years and ages $>19$ years have a population of about 3.3 million with a crude birth rate of 21.5/1000. There are a total of 1,720 health facilities, out of which 188 report using the Integrated Disease Surveillance and Response Strategy (IDSR).

\section{Surveillance evaluation methods}

We adapted the 2001 updated CDC guidelines on surveillance evaluation [19] and the Framework for Evaluating Public Health Surveillance Systems for Early Detection of Outbreaks [20] and employed both qualitative and quantitative methods to describe and evaluate the system. Stakeholders from the Kaduna State Primary Health Care Agency (KSPHCA) and Local Government Disease Surveillance Notification officers (LDSNO) were interviewed to assess their views on the usefulness and acceptability of the system. A retrospective record review of the measles case-based surveillance data from 2010- 2012 was carried out and data abstracted and analysed to determine the Positive Predictive Value (PPV) of confirmed cases [calculated as the proportion of laboratory confirmed cases true measles cases $\}$ among clinically diagnosed cases]. We assessed data quality by determining the proportion of complete weekly reports that got to the state by close of work $(4.00 \mathrm{pm})$ of Tuesday of the reporting week. The representativeness of the system was assessed by calculating the proportion of health facilities that actually report. The date of specimen collection, date of arrival at the laboratory, specimen condition on arrival, date of release of results, and Measles and Rubella IgM results were reviewed. The Proportions and rates calculated were compared with the WHO (2004) [21] recommended performance indicators to determine the quality and effectiveness of measles surveillance system.

Case and laboratory based weekly surveillance data from all the reporting focal sites (188 health facilities) were used to assess some of the system attributes.

The Standard case definition of measles was adopted to include:

Suspected measles case: Any person with fever $\left(\geq 38^{0} \mathrm{C}\right)$ and maculopapular (non-vesicular) generalized rash with cough, coryza or conjunctivitis (red eyes) OR any person in whom a clinician suspects measles.

Epidemiologically linked case: A case whose blood was not collected for laboratory investigation but had contact with another case who was laboratory confirmed and is either a family member/school mate/neighbor/playmate or who had in the preceding 2 weeks being to an area where a measles outbreak had been declared.

Confirmed measles case: A suspected case with positive IgM antibody or who is epidemiologically linked to a confirmed case in an outbreak. 
Ethical consideration: Permission to conduct the study was obtained from the Executive Secretary KSPHCA. Names of patients and addresses were omitted from the analysis.

\section{Results}

\section{Surveillance system description}

The measles surveillance system is a passive, case-based system that is operated by trained personnel's; Doctors, Disease Surveillance Notification Officers \{DSNOs\}, Laboratorians, Nurses, Community Health Extension Workers and Environmental Health Officers. Measles, being an epidemic prone disease, is reported within the context of the IDSR on a weekly basis. At health facility level, data collection is done using three [3] data collection instruments: Case Investigation Form[CIF] (001A), laboratory form (001B) and the linelist form (001C). In Kaduna State, case based information on every suspected case is inputted into the CIF, blood sample collected and laboratory information inputted into form 001B and sent to the measles reference laboratory at Yusuf Dansoho memorial hospital for confirmation [using IgM antibody ELISA]. Measles negative samples are further tested for Rubella. If the number of confirmed measles cases exceeds three [3] in any catchment area or health facility in one month, an outbreak is declared and all suspected cases are then line-listed at health facility level.

In Kaduna State, one hundred and eighty eight (188) health facilities from a total of 1,720 health facilities (10.9\%) report case based information on epidemic prone diseases on a weekly basis to the LGA level. These reports are collated by the LDSNO before the close of work on a Monday of each week and forwarded to the State epidemiologist before the close of work on Tuesday of the same week. The State epidemiologist forwards all aggregated reports from the LGAs to the national level (surveillance department) on or before close of work on Wednesday of the same week. At the State level, a copy of the surveillance database is shared with the Kaduna office of the World Health Organization (WHO). Feedback on the final case classification is given to the LDSNO and the reporting facility through the same channel used for reporting (Figure 1).

Usefulness: The analysis and interpretation of the surveillance data in the years under review showed that the surveillance system was able to detect and confirm cases of measles and nonmeasles febrile rash, however the detection of these conditions fell below the WHO recommended targets in 2011 and 2012 (Table 1).

Timeliness: Timeliness of reporting was assessed by the proportion of weekly reports from the LDSNO that gets to the State DSNO on or before 4pm (Close of work) on Tuesday of the reporting week. In 2010 and 2011, nineteen [19] LGAs [83\%] had timely reports above 80\% (WHO target), while in 2012, 15 LGAs (65\%) had timely reports above 80\%. In 2011 and 2012, Kargarko and Birnin-Gwari LGAs had the least proportion for timeliness (75\% and 39\% respectively). 


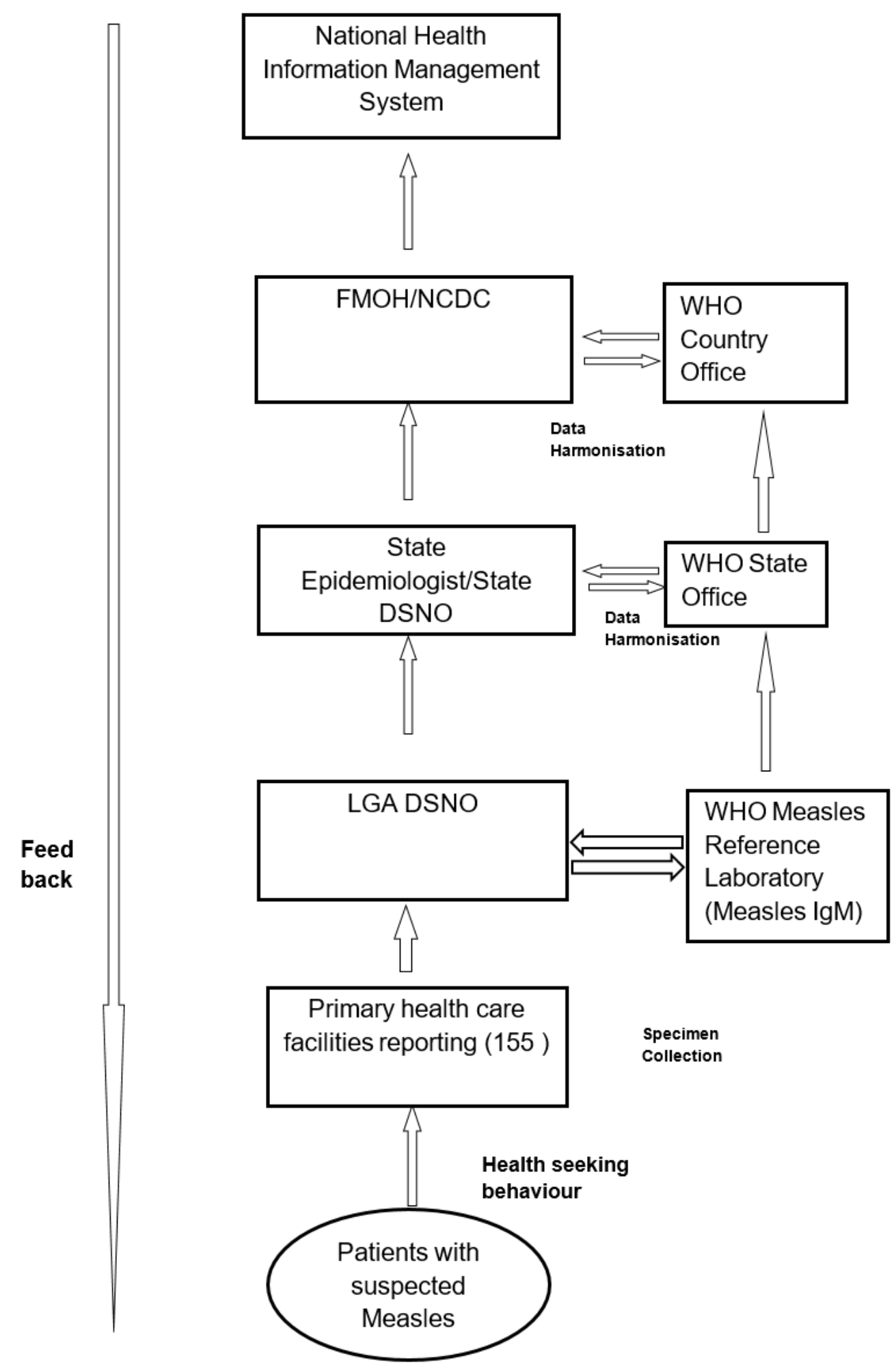

Figure 1: Measles case-based surveillance flow chart 
Table 1: Measles surveillance performance indicators for Kaduna State (2010 - 2012)

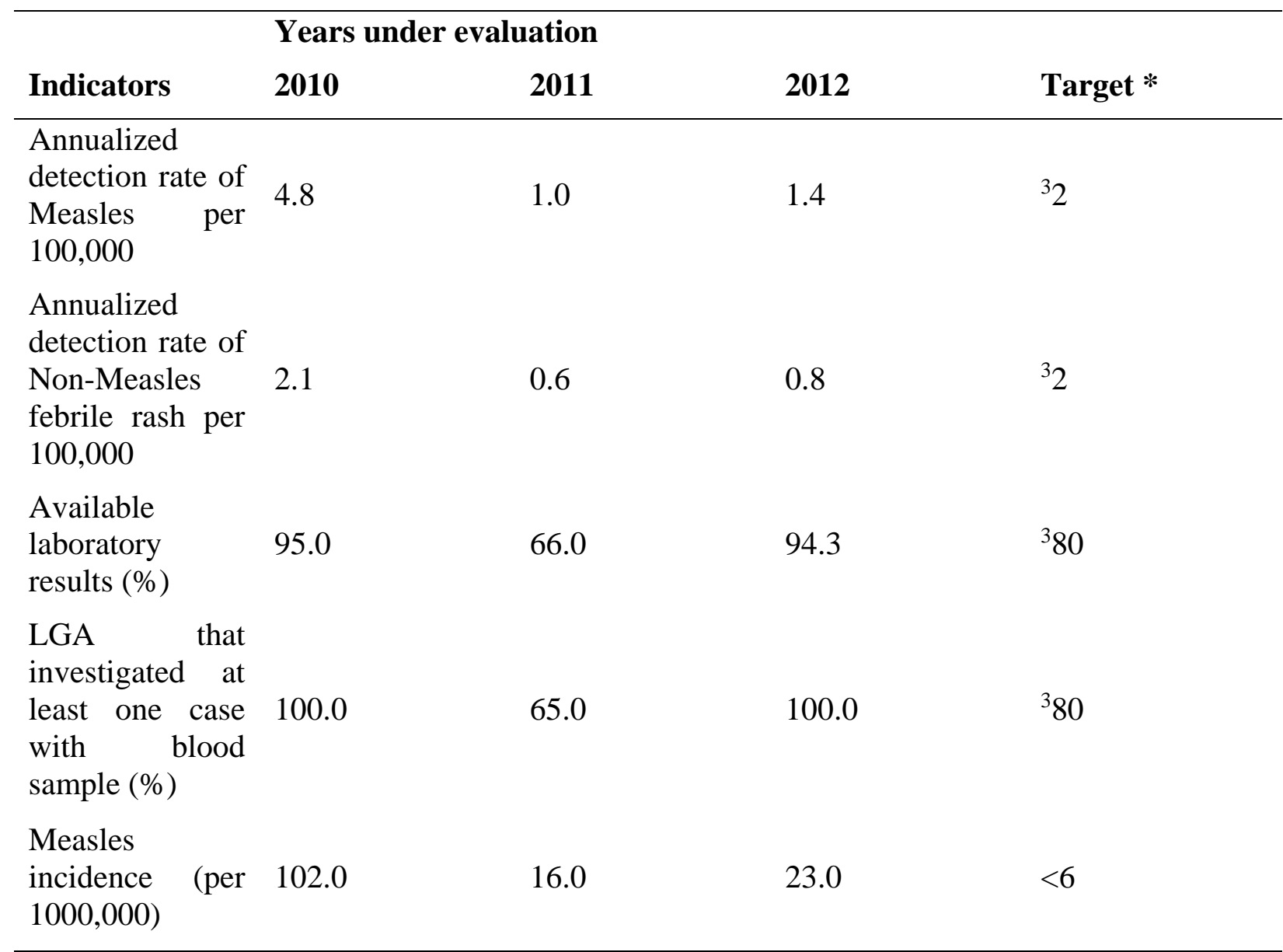

*WHO Regional office for Africa: Guideline for measles surveillance, revised in 2004 [21]

Data Quality: Data quality was assessed by the proportion of complete weekly reports that got to the State by close of work $(4.00 \mathrm{pm})$ of Tuesday of the reporting week. In $2010,80 \%$ of the LGAs had complete reports. In 2011, three [3] LGAs (13\%) had proportions lower than the $80 \%$ recommended target. While in 2012, five [5] LGAs (22\%), had proportion lower than the recommended target.

Representativeness: The Measles surveillance system is operated by different cadre of professionals; Physicians, Nurses, Laboratorians, Environmental Health Officers and Community Health Officers. All the twenty three [23] LGAs are involved in surveillance. One hundred and eighty eight (188) out of one thousand seven hundred and twenty $(1,720)$ health facilities actually report.

Positive Predictive Value: The Positive Predictive Value for the case based measles surveillance system was 53.9\% in 2010, 36.6\% in 2011 and 40.2\% in 2012 (Table 2).

Acceptability: The surveillance system was acceptable to all stakeholders and operators of the surveillance system. This acceptability is reflected in the reporting of suspected cases. 
Stability: The system is donor driven. WHO provides monthly monetary allowance and logistic support to surveillance officers. In addition, it also provides reagents and laboratory consumables for the measles reference laboratory.

Table 2: Median turn-around times for collected samples and proportion of confirmed Measles and Rubella cases in Kaduna State, 2010 - 2012

\begin{tabular}{|c|c|c|c|}
\hline $\begin{array}{l}\text { Samples turn-around times, } \\
\text { Proportion of confirmed cases }\end{array}$ & 2010 & 2011 & 2012 \\
\hline Specimen condition & †Good & †Good & †Good \\
\hline $\begin{array}{l}\text { Median interval between specimen } \\
\text { collection and receipt in the lab }\{\text { Lag } \\
\text { time[days]\} (Range) }\end{array}$ & $1(0-29)$ & $2(0-40)$ & $2(0-26)$ \\
\hline $\begin{array}{l}\text { Median interval between specimen } \\
\text { collection and release of result } \\
\{\text { Turnaround time }\} \text { /days (Range) }\end{array}$ & $7(1-24)$ & $38(16-109)$ & $11(1-105)$ \\
\hline $\begin{array}{l}\text { Median interval between onset of rash } \\
\text { to specimen collection[days](Range) }\end{array}$ & $5(0-44)$ & $5(0-43)$ & $4(0-25)$ \\
\hline Total no. of reported cases & 625 & 142 & 201 \\
\hline Confirmed measles cases & 337 & 52 & 81 \\
\hline PPV (\%) & 53.9 & 36.6 & 40.2 \\
\hline Rubella IgM confirmed cases (\%) & $31(4.9)$ & $5(3.5)$ & $39(19.4)$ \\
\hline
\end{tabular}

$†$ Adequate blood sample (5mls), Blood specimens not haemolysed

\section{Discussion}

The Measles case-based surveillance system came into effect in Nigeria in 2005 [13] following the successful implementation of the 2005 catch-up Supplemental Immunization Activity (SIA) in northern and southern Nigeria. This surveillance system forms part of the four pronged strategy for the accelerated control of measles in Nigeria. Its main objective is the reduction of measles associated morbidity and mortality. Periodic evaluation of the surveillance system is important in assessing its efficiency and effectiveness and to ascertain if the system is meeting the objective for which it was established.

In the years under review, the surveillance system was associated with a progressive decline in timeliness and completeness of reporting. This same finding had been shown to be consistent in most part of Africa especially where paper based reporting is used [22,23]. The major challenge with the decline in timeliness is that most outbreak go undetected and when finally detected would have caused a lot of harm [23]. 
The surveillance system was also shown to have a low PPV. This is reflected in the low annualized detection rate of measles and non-measles febrile rash. Since measles is endemic in Nigeria with a high prevalence [24,25], the measles surveillance system having a low PPV implies that the system would not be able to detect cases adequately. The reduced low PPV could be due to low reporting representiveness, as a relatively large number of public health facilities and most private health facilities do not report. Furthermore, the under-reporting associated with this system simply means that the surveillance system cannot predict outbreaks and most outbreaks that occur are undetected.

The evaluation of the laboratory component of the case-based system showed impressive turnaround times between time of onset of rash and the collection of specimen and also reduced times between sample collection and submission in the laboratory. With the exception of 2011, the proportion of LGAs that investigated at least one measles case with blood sample exceeded the WHO target. Also, the proportion of laboratory results made available exceeded WHO recommended target in 2010 and 2012. This finding is a plus on the measles case-based surveillance system as it will ensure the production of timely results.

The system is useful as the data it generated was used to access the performance of the measles control strategies being implemented, for instance, data emanating from the system showed a high incidence of measles in 2010. The incidence rate reduced in 2011 and 2012, but were all above the target limits set for measles elimination [21]. This finding has brought out the need to further strengthen the intervention strategies currently in place to achieve measles control targets.

\section{Conclusion}

Even though the performance of the surveillance system was not optimal, most of the major stakeholders found the surveillance system to be useful and acceptable as it was able to detect cases despite its low PPV. The surveillance system also played an important role in assessing the effectiveness of the current measles control strategies. However, the system was discovered to be unstable as it was highly donor dependent for funding and technical support.

\section{Limitation}

A major limitation of this study was our inability to determine the sensitivity of the surveillance system as there was no gold standard to compare the surveillance system with.

\section{Recommendation}

Public and private healthcare facilities currently not reporting, should be encouraged to report. Since the surveillance system had captured the increased incidence of measles above the recommended target per annum, there is need to further strengthen the accelerated measles control strategies in Kaduna State. Finally, Kaduna State should take complete ownership of the case-based surveillance system and ensure its sustainability by providing funding and logistic support.

\section{Acknowledgements}

The authors wish to thank the Nigerian Field Epidemiology and Laboratory Training Program, the surveillance officers at the various levels of surveillance in Kaduna State and the laboratory 
personnel's at the measles reference laboratory at Yusuf Dansoho memorial hospital, for giving us the opportunity to carry out this study and also providing the data which was used for the analysis.

Competing interests: No competing interests declared.

\section{References}

1. Simons E, Ferrari M, Fricks J, Wannemuehler K, Anand A, et al. Assessment of the 2010 global measles mortality reduction goal: results from a model of surveillance data. Lancet [Internet]. 2012 Jun 9 [cited 2013 Apr 15];379(9832):2173-8. Available from: http://www.ncbi.nlm.nih.gov/pubmed/22534001.

2. Li L, Qingfeng LI, Lee AR, Friberg IK, Perin J, et al. Trends in causes of death among children under 5 in Bangladesh, 1993-2004: an exercise applying a standardized computer algorithm to assign causes of death using verbal autopsy data. Popul Health Metr [Internet]. 2011 Jan [cited 2013 Oct 4];9(1):43-54. Available from: http://www.pubmedcentral.nih.gov/articlerender.fcgi?artid=3160936\&tool=pmcentrez\&r endertype $=$ abstract.

3. Grais RF, Dubray C, Gerstl S, Guthmann JP, Djibo A, et al. Unacceptably high mortality related to measles epidemics in Niger, Nigeria, and Chad. PLoS Med [Internet]. 2007 Jan [cited 2013 Mar 18];4(1):0122-9. Available from: http://www.pubmedcentral.nih.gov/articlerender.fcgi?artid=1761051\&tool=pmcentrez\&r endertype $=$ abstract.

4. Baqui AH, Black RE, Arifeen SE, Hill K, Mitra SN, et al. 1998. Causes of childhood deaths in Bangladesh : results of a nationwide verbal autopsy study [PubMed]. Bull World Health Organ. 76(2), 161-71. PubMed

5. Mandomando I, Naniche D, Pasetti MF, Cuberos L, Sanz S, et al. Assessment of the epidemiology and burden of measles in Southern Mozambique. Am J Trop Med Hyg [Internet]. 2011 Jul [cited 2013 May 10];85(1):146-51. Available from: http://www.pubmedcentral.nih.gov/articlerender.fcgi?artid=3122359\&tool=pmcentrez\&r endertype $=$ abstract.

6. Saleh AJ. 2016. Trends of measles in Nigeria: A systematic review. Sahel Med J. 19(1), 5-11. doi:http://dx.doi.org/10.4103/1118-8561.181887.

7. Hanses F, Truong AT, Ammerlaan W, Ikusika O, Adu F, et al. 1999. Molecular epidemiology of Nigerian and Ghanaian measles virus isolates reveals a genotype circulating widely in western and central Africa. J Gen Virol. 80, 871-77. PubMed http://dx.doi.org/10.1099/0022-1317-80-4-871

8. Onoja AB, Adeniji AJ, Faneye A. 2013. Measles complications in a Nigerian hospital setting. Clin Rev Opin. 5(2), 18-23. doi:http://dx.doi.org/10.5897/CRO12.008.

9. Fetuga MB, Njokanma OF, Ogunfowora OB, Abiodun R. 2007. A Ten-year study of Measles admissions in a Nigerian teaching hospital. Niger J Clin Pract. 10(1), 41-46. PubMed 
10. Weldegebriel GG, Gasasira A, Harvey P, Masresha B, Goodson JL, et al. Measles resurgence following a nationwide measles vaccination campaign in Nigeria, 2005-2008. J Infect Dis [Internet]. 2011 Jul [cited 2013 Sep 19];204 Suppl(Suppl 1):S226-31. Available from: http://www.ncbi.nlm.nih.gov/pubmed/21666165.

11. Fatiregun AA, Olowookere SA, Abubakar O, Aderibigbe A. 2009. Small-scale outbreak of measles in the Irewole local government area of Osun State in Nigeria. Asian Pac $J$ Trop Med. 2(6), 33-36.

12. Nnebe-Agumadu U. 2005. Measles control in Nigeria: the case for a two-dose vaccine policy. Niger J Paediatr. 32(3), 41-45.

13. Fatiregun AA, Adebowale AS, Fagbamigbe AF. 2014. Epidemiology of measles in Southwest Nigeria: An analysis of measles case-based surveillance data from 2007 to 2012. Trans $R$ Soc Trop Med Hyg. 108(3), 133-40. $\underline{\text { PubMed }}$ http://dx.doi.org/10.1093/trstmh/tru004

14. Adu FD, Akinwolere OAO, Uche LN. 1992. Low seroconversion rates to measles vaccine among children in Nigeria * [PubMed]. Bull World Health Organ. 70(4), 457-60. PubMed

15. Nigerian Centre for Disease Control. Weekly updates of Epidemics in Nigeria as at 1st November, 2013: 6 -9.

16. Nelesone T, Durrheim DN, Speare R, Kiedrzynski T, Melrose WD. Short communication: Strengthening sub-national communicable disease surveillance in a remote Pacific Island country by adapting a successful African outbreak surveillance model. Trop Med Int Heal [Internet]. 2006 Jan [cited 2013 May 10];11(1):17-21. Available from: http://www.ncbi.nlm.nih.gov/pubmed/16398751.

17. Isere EE, Fatiregun AA. 2014. Measles case-based surveillance and outbreak response in Nigeria; An update for clinicians and public health professionals [PubMed]. Ann Ibd Pg Med. 12(1), 15-21. PubMed

18. National Bureau of Statistics. Annual Abstract of Statistics 2012: Federal Republic of Nigeria $\quad 2012 . \quad$ Anternet]. 2 Available nigerianstat.gov.ng\nhttp://www.nigerianstat.gov.ng/report/253.

19. CDC, \& Updated Guidelines for Evaluating Public Health Surveillance Systems Recommendations from the Guidelines Working Group. 2001. MMWR Morb Mortal Wkly Rep. 50(RR13), 1-35. PubMed

20. Buehler JW, Hopkins SR, Overhage MJ, Sosin DM, Tong V. 2004. Framework for Evaluating Public Health Surveillance Systems for Early Detection of Outbreaks Recommendations from the CDC Working Gr [PubMed]. MMWR. 53(RR05), 1-11. $\underline{\text { PubMed }}$

21. WHO. Guidelines for Measles Surveillance. 2004: 1 - 38.

22. Garcel HG, Hernandez TMF, Abdo EAB, Arias AV. 2014. Evaluation of the timeliness and completeness of communicable disease reporting: Surveillance in the Cuban Hospital, Qatar [PubMed]. Qatar Med J. (1), 50-56. PubMed 
23. Adokiya MN, Awoonor-Williams JK, Beiersmann C, Olaf M. 2015. Evaluation of the reporting completeness and timeliness of the integrated disease surveillance and response system in northern Ghana [Internet]. BMC Public Health. 15(1), 3-8. http://www.scopus.com/inward/record.url?eid=2-s2.0-

84924260158\&partnerID=40\&md5=e9e9d83976615965f5fcc4a571ebe270. $\quad \underline{\text { PubMed }}$ http://dx.doi.org/10.1186/s12889-015-1397-y

24. Adeboye M, Adesiyun O, Adegboye A, Eze E, Abubakar U, et al. 2011. Measles in a tertiary institution in Bida, Niger state, Nigeria: Prevalence, immunization status and mortality pattern. Oman Med J. 26(2), 114-17. http://dx.doi.org/10.5001/omj.2011.28

25. Faneye AO, Adeniji JA, Olusola BA, Motayo BO, Akintunde GB. 2015. Measles Virus Infection Among Vaccinated and Unvaccinated Children in Nigeria. Viral Immunol. 28(6), 304-08. PubMed http://dx.doi.org/10.1089/vim.2014.0118 